\title{
CONTRIBUIÇÕES DA OBRA PEDAGOGIA DO OPRIMIDO AO (RE) PENSAR DA FORMAÇÃO DE EDUCADORES DE JOVENS E ADULTOS
}

\section{Maria Clarisse Vieira ${ }^{\mathrm{i}}$}

\begin{abstract}
Resumo: O artigo visa a (re) discutir o tema da formação de educadores na educação de jovens e adultos à luz da contribuição da educação popular e da Pedagogia libertadora de Paulo Freire. Em termos teórico-metodológicos, o texto contextualiza aspectos históricos relativos à formação docente em educação de jovens e adultos em diálogo com as pesquisas desta área. Discute-se como as categorias dialogicidade, educação para mudança e inédito viável, presentes na obra Pedagogia do Oprimido e em outros escritos do autor colaboram na construção de uma proposta de formação de educadores no contexto de uma concepção transformadora e humanista de educação.
\end{abstract}

Palavras chaves: formação de educadores. Educação de jovens e adultos. Paulo Freire, dialogicidade. inédito viável.

\section{CONTRIBUTIONS OF THE WORK PEDAGOGY OF THE OPPRESSED TO (RE) THINK TRAINING OF EDUCATION TEACHERS OF YOUTH AND ADULTS}

\begin{abstract}
The article aims to (re) discuss the theme of the formation of educators in the Education of Young and Adults in the light of the contribution of popular education and Paulo Freire 's liberating pedagogy. In theoretical-methodological terms, the article contextualizes historical aspects related to teacher training in Education of Young and Adults in dialogue with research in this area. It is discussed how the categories dialogic, education for change and untested feasibility, present in the work Pedagogy of the Oppressed and in other writings of the author collaborate in the construction of a proposal of training of educators in the context of a transformative and humanistic conception of education.
\end{abstract}

Keywords: teacher training. youth and adult education. Paulo Freire. Dialogical. untested feasibility.

\section{Introdução}

Em 2018, comemoram-se cinquenta anos da publicação da obra Pedagogia do Oprimido, escrita por Paulo Freire, no período do exílio, no Chile. Como reconhecimento à contribuição de Freire à educação, em todo o País diversas instituições educativas realizaram eventos, nos quais foram debatidos o legado desse educador e a atualidade do seu pensamento. Lembrar a memória de Paulo Freire, por meio da discussão deste livro implica em nos situar, ao lado dos "esfarrapados do mundo e aos que nele se descobrem, e, assim, descobrindo-se com eles sofrem, mas, sobretudo com eles lutam”. De forma semelhante, (re) discutir o tema da formação de educadores na Educação de Jovens e Adultos (EJA) à luz de algumas categorias oriundas desta 
obra significa se posicionar em favor da construção de políticas públicas que reafirmam o direito à educação pública de qualidade para todos, em especial, os sujeitos da EJA.

Este artigo visa discutir a contribuição das práticas de educação popular na formação do educador na área de EJA. Para isso, busca se ancorar na Pedagogia libertadora de Freire, em especial, algumas categorias presentes na obra Pedagogia do Oprimido, que iluminam a construção de uma proposta de formação de educadores dentro de uma concepção transformadora de educação. $O$ artigo está organizado da seguinte forma: inicialmente, contextualizam-se aspectos relativos à formação docente em EJA, dialogando com as pesquisas no campo da educação. Em seguida, discutem-se como as categorias dialogicidade, educação para mudança e inédito-viável presentes na obra Pedagogia do Oprimido e em outros escritos do autor colaboram na reflexão sobre a formação inicial e continuada de educadores na EJA.

\section{A formação de educadores na EJA: desafios na construção da educação popular}

Em artigo no qual analisa a formação de educadores, Maria Amélia C. Giovanetti (2005) indica duas marcas identitárias da EJA. A primeira é a origem social dos educandos, ou seja, seu pertencimento às camadas populares; a segunda referência é sua concepção de educação, que incorpora o legado da educação popular. Apoiando-se em Romanelli (2003), a autora conceitua camadas populares como uma das categorizações utilizadas para referir-se à população pobre, que vivencia o não atendimento a questões básicas de sobrevivência (saúde, trabalho, alimentação, educação, etc).

Com base nessa categorização, Giovanetti assinala que o campo da EJA atende jovens, adultos e idosos que, não tendo tido o acesso e/ou permanência na escola, em idade que lhes era de direito, retornam à escola, buscando o resgate desse direito. Nessa perspectiva, lida com sujeitos portadores de trajetórias escolares truncadas e que se encontram enredados em teias mais amplas de vulnerabilidade social. Esses sujeitos, ao mesmo tempo em que vivenciam processos de exclusão social, materializados em processos de segregação cultural, espacial, étnica e econômica, experimentam, cotidianamente, o abalo de seu sentimento de pertença social e o bloqueio de perspectivas de futuro social. As propostas de educação de jovens e adultos sob a influência do ideário da educação popular, ao enfocarem esse conflito, assumem uma atitude no sentido de superar esse quadro de desigualdade social, que se faz presente nos processos escolares e não escolares.

Historicamente, na América Latina e particularmente no Brasil a Educação Popular emerge como contraposição à educação formal escolar, à medida que esta inculcava valores que 
reafirmavam uma sociedade dominada hegemonicamente pelo modo de produção capitalista. Esta origem ligada aos movimentos sociais, por intermédio de atividades pedagógicas e culturais de teor político-ideológico, identifica a educação popular como uma das organizações superestruturais da sociedade capitalista, que tem uma posição de classe definida em sua origem: a das classes trabalhadoras.

Autores como Paulo Freire discutem a relevância da educação popular no contexto da educação de adultos. Segundo ele, não somente no Brasil, como em outros países da América Latina, a Educação de adultos vivenciou um processo de amadurecimento. Este amadurecimento relaciona-se à sua aproximação a Educação popular, que é entendida como uma vocação da educação. (BRANDÃO, 2002). Este autor afirma que a educação popular volta-se àqueles até então sistematicamente deixados ao longo de suas margens e é pensada, proposta e praticada a partir da condição das classes subalternas e de uma visão de mundo das classes populares. Segundo ele, trata-se de uma proposta dialógica, que busca participar de transformações efetivas, primeiro no nível das consciências individuais e de culturas coletivas, depois e por extensão, na esfera das regiões entrelaçadas e nas estruturas sociais regidas por princípios, valores e motivos (anti) capitalistas (BRANDÃO, 2002).

Em direção semelhante Freire (2000) argumenta que a educação de Adultos é melhor entendida quando é situada como Educação Popular, ou seja:

O conceito de Educação de Adultos vai se movendo na direção da Educação Popular na medida em que a realidade começa a fazer algumas exigências à sensibilidade e à competência cientifica dos educadores e das educadoras. Uma destas exigências tem a ver com a compreensão crítica dos educadores do que vem ocorrendo na cotidianidade do meio popular. Não é possível que educadoras e educadores pensem apenas os procedimentos didáticos e os conteúdos a serem ensinados aos grupos populares. Os próprios conteúdos a serem ensinados não podem ser totalmente estranhos àquela cotidianidade. O que acontece, no meio popular, nas periferias das cidades, nos campos, trabalhadores urbanos e rurais reunindo-se para rezar ou para discutir seus direitos. Nada pode escapar à curiosidade arguta dos educadores envolvidos na prática da educação popular. (FREIRE, 2000, p. 15-16).

A compreensão de Freire sobre educação Popular explicita que esta não pode se restringir ao cumprimento de programas, planos de cursos, planos de disciplinas, elaborados à revelia dos educandos numa concepção bancária e autoritária da educação. Segundo ele, os educadores e grupos populares compreendem que Educação Popular é, sobretudo, o processo permanente de reflexão sobre a militância, ou seja, de avaliar a sua capacidade de se mobilizar em direção a objetivos próprios. Nessa visão, o ato educativo compreendido como ato político, não se deixa aprisionar na estreiteza burocrática de procedimentos escolarizantes. 
Segundo Freire, ao lidar com o processo de conhecer, a prática educativa é tão interessada em possibilitar o ensino de conteúdos às pessoas quanto em sua conscientização. Nesse aspecto, a

\footnotetext{
Educação Popular de corte progressista, democrática, superando o que chamei, na "Pedagogia do Oprimido", 'educação bancária', tenta o esforço necessário de ter no educando um sujeito cognoscente, que, por isso, mesmo se assume como um sujeito em busca de, e não como a pura incidência da ação do educador. (FREIRE, 2000, p.16).
}

A Educação de Jovens e Adultos é uma modalidade educativa que possui características peculiares, que envolvem seus sujeitos e práticas. O público que integra esta modalidade é, em grande parte, formado por pessoas pobres, negras, desempregadas ou no mercado informal. São pessoas pertencentes a coletivos sociais historicamente marginalizados, tais como quilombolas, população do campo e de periferias urbanas, mulheres e homens negros, pessoas em situação de rua, pessoas privadas de liberdade, etc. Em meio a toda essa diversidade, todos possuem algo em comum: não tiveram a oportunidade de acesso e permanência na escola, seja na infância ou na juventude.

Considerando a pluralidade que caracteriza o público da EJA, propostas pedagógicas e curriculares precisam ser pensadas no quadro de concepções voltadas à formação humana que contemplem suas subjetividades, seus processos de formação histórico-sociais, no sentido de atender e se adequar às necessidades desse público.

\section{Diálogo sobre a formação docente: uma reflexão histórica}

Nos últimos anos algumas universidades públicas têm desempenhado um importante papel na formação docente para a EJA, contribuindo com experiências enriquecedoras e despertando a academia para essa problemática. No entanto, parte dessas instituições ainda não tem assumido a EJA como parte integrante de suas políticas e ações. A ausência de disciplinas ou de espaços curriculares nos cursos de formação inicial e continuada tem dificultado o despertar e/ou aprofundamento das reflexões sobre as diversas dimensões que constituem essa modalidade educativa.

Segundo Fávero e Rummert (1999, p.43), a ausência de preocupação com a formação de professores de EJA possui raízes históricas e relaciona-se a um conjunto de representações arraigadas na cultura que perpassa a educação e outras práticas sociais. Dentre essas representações, há aquelas que inspiram muitas práticas de EJA, concebendo-a como "algo a ser adaptado, ou mesmo reproduzido a partir das ações desenvolvidas junto à população infantil”. 
Nessa concepção, o jovem e o adulto com nenhuma ou pouca escolarização são vistos como "alguém que deixou de cumprir, por deficiências próprias, a tarefa que lhe cabia na infância: estudar”. Em decorrência, as práticas pedagógicas de EJA são infantilizadas, sendo o jovem e o adulto, em certa medida, percebidos e tratados como "crianças grandes", "marmanjos" que não aprenderam na "idade apropriada".

Estudos sobre a constituição histórica da EJA no Brasil revelam que, há muito tempo, a formação dos professores para a EJA representa uma preocupação. A primeira Campanha Nacional de Educação de adolescentes e Adultos, iniciada em 1947, ocorreu basicamente por meio do trabalho do voluntariado. Ela foi sistematicamente criticada por não preparar de forma adequada os professores que atuavam com esse público. Embora essa Campanha tenha contribuído para a criação dos serviços estaduais de educação de adultos em diversas unidades da Federação, foram feitas muitas críticas à organização e ao funcionamento desses órgãos nos Estados. Segundo Beisiegel (1974), desde o início o ensino supletivo dependia das instalações, dos quadros administrativos e do pessoal docente do ensino primário fundamental comum. Para ele,

O ensino supletivo definiu-se como uma réplica do ensino infantil, ministrado a adolescentes e adultos. Delegados regionais, inspetores, diretores de escolas e professores levavam para as suas novas tarefas os velhos hábitos de trabalho e os conteúdos da ação educativa que desenvolviam no ensino primário. (BEISIEGEL,1974, p.118-119).

A precariedade dos serviços oferecidos por meio das campanhas de alfabetização e do ensino supletivo nos Estados foi bastante criticada durante o II Congresso de Educação de Adultos, ocorrido em 1958, apontando-se a necessidade de rediscutir as formas e conteúdos da EJA. Nesse contexto, multiplicaram-se em todo país movimentos de educação e cultura popular, dentro de uma concepção que incorporava a perspectiva de transformação social, fato que evocou a influência das ideias de Paulo Freire.

Desde então, a questão da formação e profissionalização do educador de EJA vem ocupando um espaço importante nas discussões teóricas da área. Algumas mudanças foram introduzidas na legislação educacional. A Lei 5692/71 reservou um capítulo específico a essa área, intitulado ensino supletivo. Apesar do caráter tecnicista dessa legislação, em um dos seus artigos consta a necessidade de preparação do professor, tendo em vista atender de forma adequada esse público. A Lei 9394/96, aponta como compromisso a formação inicial dos professores do ensino básico em nível superior, em cursos de licenciatura plena. Ressalta a importância da formação de profissionais da educação, a fim de se alcançar uma qualidade 
efetiva na educação ofertada aos educandos que frequentam o ensino noturno e as classes de ensino regular de jovens e adultos.

O item VIII das "Diretrizes Curriculares Nacionais para a Educação de Jovens e Adultos" trata da Formação docente para EJA. Nele, consta que "o preparo de um docente para a EJA deve incluir, além das exigências formativas para todo e qualquer professor, aquelas relativas a complexidade diferencial desta modalidade de ensino". O documento discute as especificidades de aprendizagem dos sujeitos da EJA, o que demanda, por parte dos docentes, a constituição de projetos pedagógicos que considerem modelos apropriados a suas características, interesses e expectativas. Ele também estabelece que as instituições que se ocupam da formação de professores, possibilitadora das licenciaturas e outras habilitações profissionais, são chamadas a incluir nos seus currículos e programas a realidade da EJA. A construção de uma política de formação docente para a EJA, assumida por algumas universidades, ao lado de Secretarias de Educação e outras instituições privadas sem fins lucrativos, implica "um processo em via de consolidação e dependente de uma ação integrada de oferta desta modalidade nos sistemas". (BRASIL, 2001, p. 155).

Apesar dos avanços alcançados na legislação educacional, a formação docente na área de educação de jovens e adultos representa um desafio que precisa ser assumido por governos e sociedade civil, pois se observa ainda hoje, na prática pedagógica da maior parte das escolas, a predominância de uma "oferta compensatória, aligeirada, residual, em grande parte inadequada às necessidades dos estudantes da EJA no seu processo de escolarização." (SERRA et al 2017, p. 27). Ou seja, a escolarização dos sujeitos da EJA segue baseada na apropriação dos saberes formais hegemonicamente estabelecidos, entendendo os saberes dos sujeitos da EJA como inferiores. (OLIVEIRA; COUTINHO; 2013).

Para mudar este quadro é necessário pensar uma formação inicial e continuada de professores que além de qualidade, incorpore os princípios de uma pedagogia libertadora, tal como anunciava Paulo Freire, desde os anos 1960, em sua Pedagogia do Oprimido.

\section{Contribuições de Paulo Freire para (re) pensar a formação em EJA: uma (re) leitura da Pedagogia do Oprimido}

Ao avaliar o legado que o movimento de educação popular trouxe às reflexões na Pedagogia Arroyo (2005) indica sua contribuição na revisão de antigas concepções pedagógicas sobre a formação humana no diálogo com a educação do povo. De acordo com esse autor, ao longo de sua história, a EJA constituiu-se em um campo radical do repensar e do fazer 
pedagógicos. Para ele, as trajetórias truncadas e fragmentadas que os jovens e adultos carregam colocam em xeque a linearidade do pensar e do fazer pedagógico, interrogando as bases que estruturam a docência e a Pedagogia. Segundo ele:

O sonho da escola é que todas as trajetórias escolares fossem lineares, sempre progredindo, sem quebras, subindo as séries sem escorregar, aprendendo em progressão contínua, em ritmos acelerados. Quaisquer alunos(as) que não seguirem essa linearidade serão catalogados como alunos com problemas de aprendizagem, de ritmos lentos, de progressão descontínua, desacelerada. A maior parte ou a totalidade das trajetórias dos alunos e alunas que volta a EJA não se enquadram nessa esperada linearidade. Contrapõem-se a essa linearidade. Contestam-na. Interrogam as bases teóricas (se é que existem) dessa suposta linearidade nos processos de aprender e de desenvolvimento humano. (ARROYO, 2005, p.36).

Em consonância com esta perspectiva desde os anos 1960, nos principais escritos de Paulo Freire encontra-se uma crítica às estruturas de dominação presentes na cultura e na educação, propondo-se, por meio do trabalho pedagógico realizar uma ação sobre a cultura "com vistas a torná-las culturas pensadas como sistemas históricos de símbolos e de significados, um caminho pioneiro e coletivo de ações transformadoras de toda a sociedade". (BRANDÃO, 2002, p. 134).

A magnitude das ideias e pensamento de Freire possibilita que sua obra possa ser interpretada em diversos campos do conhecimento, sobretudo, se concebermos a educação como fenômeno amplo que envolve diferentes fatos, fenômenos e dimensões da vida em sociedade, não se restringindo ao contexto escolar. Escolhemos tratar neste texto, como as categorias dialogicidade, educação para mudança e inédito-viável presentes na obra Pedagogia do Oprimido e em outros escritos do autor podem colaborar na reflexão sobre a formação de educadores na EJA.

A obra Pedagogia do Oprimido foi escrita em 1968, no período em que Paulo Freire encontrava-se exilado no Chile. Neste período, Freire trabalhou com Jacques Chonchol, que coordenava trabalhos ligados à reforma agrária no Instituto de Capacitação e Investigação em Reforma Agrária (ICIRA). Além da atuação neste Instituto, os anos vividos neste país foram importantes na produção escrita de Paulo Freire, uma vez que conseguiu revisar e publicar o livro Educação como Prática da Liberdade, além de escrever seu livro mais famoso: Pedagogia do Oprimido (BARRETO, 1998)

Pedagogia do Oprimido foi escrito, portanto, com base nas reflexões e vivências do autor ao longo de sua trajetória no exílio e no Brasil. Nesta obra, traz uma contribuição significativa a área de educação ao propor uma educação humanista e libertadora, que tem no diálogo uma das categorias centrais para uma pedagogia crítica. Em linhas gerais, o autor afirma que a pedagogia 
das classes dominantes, com seus métodos e técnicas peculiares, não pode servir a libertação dos oprimidos, mas a manutenção da ordem vigente. Neste sentido, como afirma Fiori, na apresentação do mesmo livro, "a educação como prática da liberdade, postula necessariamente uma "pedagogia do oprimido" (Fiori, apud FREIRE 1987, p. 9), ou seja:

A educação liberadora é incompatível com uma pedagogia que, de maneira consciente e mistificada, tem sido prática de dominação. A prática da liberdade só encontrará adequada expressão numa pedagogia em que o oprimido tenha condições de reflexivamente, descobrir-se e conquistar-se como sujeito de sua própria destinação histórica (Fiori,apud FREIRE, 1987, p. 9).

É importante reiterar que a maior parte dos sujeitos que frequentam as classes de Educação de Jovens e Adultos carregam consigo as marcas da opressão e da exclusão. Estes homens e mulheres oprimidos encontram-se mergulhados na cultura do silêncio, não se percebendo como sujeitos da história. É mister elaborar uma pedagogia dialógica que promova o dessilenciamento destes sujeitos. Para isso, Freire estabelece algumas premissas para o diálogo verdadeiro. Dentre estas condições destacam-se o amor, a humildade, a fé no ser humano, a confiança, a esperança e o pensar crítico.

Segundo ele, para desenvolver uma relação dialógica, o educador necessita possuir uma profunda fé nos homens e nas mulheres, sem o qual um trabalho crítico e compromissado com a transformação da realidade torna-se inviável.

A fé nos homens é um dado a priori do diálogo. Por isso existe antes mesmo de que ele se instale. O homem dialógico tem fé nos homens antes de se encontrar frente a frente com eles. Esta, contudo, não é uma ingênua fé. O homem dialógico que é crítico, sabe que, se o poder de fazer, de criar, de transformar, é um poder dos homens, sabe também que podem eles, em situação concreta, alienados, ter este poder prejudicado. Esta possibilidade, porém, em lugar de matar no homem dialógico a sua fé nos homens, aparece a ele, pelo contrário, como um desafio ao qual tem de responder. Está convencido de que este poder de fazer e transformar, mesmo que negado em situações concretas, tende a renascer. Pode renascer. Pode constituir-se. Não gratuitamente, mas na e pela luta por sua libertação. (FREIRE, 1987 p.81)

Considerando que independente de ter frequentado os espaços formais de educação, o ser humano possui diversos conhecimentos construídos ao longo da sua trajetória faz-se necessário romper com a hierarquização do saber e com as relações assimétricas presentes entre educadores e educandos na EJA. Para isso é mister construir uma relação horizontal e dialógica, que segundo Freire se inicia na "busca do conteúdo programático", que inclui saberes diferentes que não podem ser impostos, mas cujo ponto de partida é a realidade existencial do educando. Isto é, uma educação libertadora na EJA, busca promover a interação de saberes e conhecimentos 
oriundos de campos diversos, com vistas a propiciar a humanização dos educandos, ou seja, a sua busca por ser mais. Ressalta-se que o conceito de ser mais elaborado por Paulo Freire, referese ao processo de inacabamento humano e a sua educabilidade, pois, "aí se encontram as raízes da educação mesma, como manifestação exclusivamente humana. Isto é, na inconclusão dos homens e na consciência que dela têm. Daí que seja a educação um que fazer permanente". (FREIRE, (1987, p.73),

No que tange a realidade dos sujeitos que frequentam a EJA, é importante considerar que sua experiência de vida confere a essa modalidade educativa uma identidade que a distingue da escolarização regular sequencial, com demandas educativas peculiares, características diversas de aprendizado, práticas adequadas de trabalho, representações também diferenciadas acerca da idade cronológica e do tempo de formação. Ou seja, faz-se necessário articular o contexto de vida dos educandos aos saberes escolares como conteúdo básico, reconhecendo os educandos da EJA como seres históricos e produtores culturais. (SOARES; PEDROSO, 2013; FREIRE, 1987).

Vale destacar que Freire valoriza tanto os conhecimentos escolares como os não escolares, apontando o diálogo como ferramenta indispensável na recuperação da humanidade roubada dos educandos. Nesta visão, o diálogo é visto como "o encontro dos homens, mediatizados pelo mundo para pronunciá-lo, não se esgotando (...) na relação eu-tu". (idem, 1987, p.78). A prática pedagógica, portanto, tem como base o processo de conscientização crítica da realidade que é forjado pela relação compromissada entre os sujeitos. Essa educação tem como cerne uma pedagogia problematizadora, humanista e crítica, que se efetiva pelo amor ao próximo e à vida, regadas por relações de confiança e imbuídas de uma visão emancipadora.

O diálogo demanda, portanto, que a dicotomia ensino-aprendizagem seja superada uma vez que numa perspectiva libertadora de educação não pode ocorrer processos de invasão cultural, no qual o educador apenas transfere o conhecimento a alguém.

\footnotetext{
Essa seria uma proposta antidialógica e incompatível com uma educação humanista e libertadora, uma vez que toda invasão cultural pressupõe a conquista, a manipulação e outros instrumentos de domesticação. Para uma educação libertadora, o conhecimento tem que ser dialógico, sem espaço para invasões e manipulações, ações que não cabem quando se busca compreender as relações homem-mundo, e a transformação constante da realidade. (SOARES; PEDROSO, 2013, p. 258).
}

Por meio desta pedagogia problematizadora, busca-se romper com as contradições presentes na dualidade opressor-oprimido. Para isso, tanto o homem quanto a mulher são vistos como sujeitos históricos, em constante transformação, no entanto, eivados de contradições que lhes acarretam desumanização. Uma destas contradições encontra-se no fato do oprimido poder 
hospedar em si a sombra dos opressores. Para expulsar o opressor dentro de si, faz se necessária uma pedagogia que o auxilie na superação desta realidade dicotômica, por intermédio da conscientização. $\mathrm{O}$ ato de libertar-se das forças e formas opressoras exige além de atitude radical, o exercício permanente de autonomia e ação-reflexão-ação.

Quem, melhor que os oprimidos se encontrará preparado para entender o significado terrível de uma sociedade opressora? Quem sentirá melhor que eles, os, efeitos da opressão? Quem mais que eles para ir compreendendo a necessidade de libertação? Libertação a que não chegarão pelo acaso, mas pela práxis de sua busca; pelo conhecimento e reconhecimento da necessidade de lutar por ela. (FREIRE, 1987, p. 31).

Esta transformação somente poderá partir do oprimido. Ou seja, cabe a ele tornar possível o movimento práxico de ação e reflexão, que o levará a superar esta contradição instalada. Neste sentido, a palavra não é privilégio de alguns e sim direito de todos os seres humanos, que mergulhados na realidade, são capazes de refletir e mudar o que é estabelecido como verdade. É por intermédio da palavra e da materialidade da vida que o (a) sujeito (a) constrói sua consciência e sua ação no mundo para transformá-lo.

Paulo Freire quando discute a essência do diálogo identifica na palavra o processo pelo qual se constitui o diálogo verdadeiro. A palavra, para que se faça transformadora da realidade, necessita ser resultante da ação e da reflexão. "Não há palavra verdadeira que não seja práxis. Daí dizer que a palavra verdadeira seja transformar o mundo" (FREIRE, 1987, p.77). Ou seja, o diálogo envolve a práxis social, movimento que inclui o compromisso entre a palavra dita e a ação humana, no sentido de transformação criadora.

O processo de libertação pode ser sintetizado em dois momentos: um primeiro no qual ao desvelar sua opressão, desmistifica sua realidade, comprometendo-se com a práxis. Um segundo, no qual transforma sua realidade e simultaneamente transforma a pedagogia em que se encontra, num processo de libertação permanente de todos os homens. No entanto, adverte Freire, a educação para a liberdade tem que ser um ato de amor. Amor ao mundo e aos homens. Não é possível o diálogo como ato de criar e recriar o mundo, se não existir amor, porque este já é o próprio diálogo. Nas relações de dominação e opressão não existe amor à vida, mas uma relação necrófila. As relações de dominação e opressão são permeadas pelo sadismo de quem domina e o masoquismo de quem é dominado (FREIRE, 1987).

Como posso dialogar, se alieno a ignorância, isto é, se a vejo sempre no outro, nunca em mim? Como posso dialogar se me admito como um homem diferente, virtuoso por herança, diante dos outros, meros "isto", em que não reconheço outros eu? Como posso dialogar, se me sinto participante de um gueto de homens puros, donos da verdade e do saber, para quem todos os que estão fora são "essa gente", ou são "nativos inferiores"? 
Como posso dialogar, se parto de que a pronúncia do mundo é tarefa dos homens seletos e que a presença das massas na história é sinal de sua deterioração que devo evitar? Como posso dialogar, se me fecho à contribuição dos outros, que jamais reconheço, e até me sinto ofendido com ela? Como posso dialogar se temo a superação e se, só em pensar nela, sofro e definho? (FREIRE, 1987, p. 80).

Freire explicita que não existe neutralidade na educação. Ou se constrói uma concepção que educa para a manutenção da realidade opressora e aliena o ser humano da sua realidade concreta; ou se constrói uma prática educativa que liberta por intermédio do desenvolvimento do senso crítico dos sujeitos, do diálogo e da relação entre os sujeitos baseada na horizontalidade.

Neste aspecto, ao discutir a formação de educadores na Educação de Jovens e Adultos faz-se necessário refletir como estes pressupostos podem estar presentes na prática cotidiana do professor. Para isso, Paulo Freire anuncia, mesmo que brevemente o conceito de inédito viável na obra Pedagogia do Oprimido. Posteriormente, este conceito foi aprofundado por outros autores.

É importante mencionar que este conceito surgiu, inicialmente, relacionado à ideia que André Nicolai defendeu como "soluções praticáveis despercebidas" (FREIRE, 1987, p. 107). Ou seja, não se tratava apenas de obter soluções prontas, mas de sonhar com a possibilidade de ao agir no mundo, transformá-lo. Nestes termos, inédito viável também pode ser relacionado às ideias de utopia e de sonho possível.

Segundo Danilo Streck

Essa busca de inéditos-viáveis ou do sonho possível pode acontecer no cotidiano da sala de aula, na gestão de escolas ou de sistema de ensino, no trabalho com saúde pública, em movimentos sociais e em qualquer lugar onde se aceita a premissa de que o futuro não precisa ser a repetição do presente e que a educação tem um papel em projetar e construir este outro futuro. A educação, está certo, não tem o poder da economia, o voto dos políticos ou as armas do exército. Mas, paradoxalmente, para Freire, é nesta sua fraqueza que reside sua força. A palavra, quando unida à ação, tem um poder mágico. (STRECK, 2007, p. 7).

E é nesta ideia de sonho possível, que a formação de educadores de EJA precisa ser compreendida. Educação que seja pautada numa perspectiva dialógica e crítico- emancipatória, no qual os professores se engajam na transformação da realidade, por meio da superação das situações-limites. Na visão de Freire, as situações-limites constituem-se em freios que impedem a mudança, pois são vistas como barreiras, ou "determinantes históricas, esmagadoras, em face das quais não cabe outra alternativa, senão adaptar-se". (FREIRE, 1987, p. 94).

Segundo Freire, a tendência então "é vislumbrar no inédito viável, ainda como inédito viável, uma 'situação limite' ameaçadora que por isso mesmo, precisa não se concretizar. Daí 
que atuem no sentido de manterem a 'situação limite' que lhe é favorável” (FREIRE, 1987, p. 94)

O obnubilamento da visão acaba impedindo que as situações-limites sejam superadas, alcançando-se o inédito viável. Daí a importância da educação libertadora/problematizadora buscar a correspondência dos temas geradores com a percepção que os homens tenham a respeito da realidade na qual estão imersos. Trazer estas ideias para o campo da formação de educadores de EJA implicaria dizer que os docentes instigados pelas discussões na e da formação podem se engajar na transformação do real concreto, constituindo os inéditos-viáveis. Para isso, é importante inserir nos programas e ações de formação de educadores em EJA uma concepção que, ao incorporar o ideário da educação popular, "explicita sua intencionalidade: educação - um processo de formação humana que visa a contribuir para o processo de mudança social" (GIOVANETTI, 2005, p. 244).

Em relação a este aspecto, Giovanetti relembra que a sociedade brasileira encontra-se estruturada por fortes marcas do nosso passado colonial e escravocrata, que dificultam os processos de mudança social. É no interior desse cenário, marcado por lutas e contradições, que educadores e educandos poderão traçar "estratégias de superação de toda uma herança histórica que insiste em prolongar sua presença em prejuízo da mudança”. (idem, p. 248) Retomando as ideias de Paulo Freire, a autora distingue os conceitos de condicionamento e determinismo, pois somente na história, como possibilidade e não como determinação, "se percebe e se vive a subjetividade em sua dialética relação com a objetividade. É percebendo e vivendo a história como possibilidade que experimento plenamente a capacidade de comparar, de ajuizar, de escolher, de decidir, de romper”. (FREIRE, 2000, p. 57). Assim, as mudanças tanto podem ocorrer em nível micro, nas relações interpessoais, quanto em nível macro, envolvendo transformações mais abrangentes. Se a mudança é vista como algo que perpassa a relação educativa, quando ocorre no campo da EJA, adquire novas configurações.

\footnotetext{
Esse processo não se restringe, então, à mudança de caráter micro, pessoal; ele poderá alcançar a dimensão macro, coletiva, social. Uma vez que os alunos - jovens e adultos pertencentes às camadas populares vivenciam as ressonâncias da condição de exclusão social, o processo educativo vivenciado por eles poderá atingir a dimensão subjetiva, criando estratégias de superação da inferioridade, desnaturalizando-a. O mesmo processo educativo poderá ultrapassar o universo micro, pessoal, subjetivo e alcançar o grupal, o coletivo, chegando a contribuir para mudanças de caráter social. (GIOVANETTI, 2005, p. 249).
}

Com base em Freire essa autora afirma que a relação educativa tanto pode favorecer a permanência ou agravamento da condição de subalternidade, por parte dos setores populares, 
quanto pode favorecer os movimentos de resistência por parte desses sujeitos. Segundo ela, ao serem considerados seres inacabados e tomarem a consciência do seu inacabamento, os sujeitos jovens e adultos poderão ir mais além da determinação, pois, como afirma Freire, "se a educação não pode tudo, alguma coisa fundamental a educação pode. Se a educação não é a chave das transformações sociais, não é também simplesmente reprodutora da ideologia dominante”. (FREIRE, 1996, p. 126).

Nesta visão, os educandos, passam a ser compreendidos como sujeitos socioculturais. Conceber os jovens e adultos das camadas populares como sujeitos significa enxergá-los para além da identidade de aluno, rompendo com a ideia de que são defasados, lentos, incapazes e toda uma série de rótulos vinculados ao universo da escolaridade. Significa acreditar em sua capacidade de superar os dilemas intrínsecos à sua condição de exclusão social. Conceber os educandos da EJA como sujeitos implica reconhecer que as "trajetórias sociais e escolares truncadas não significam sua paralisação nos tensos processos de sua formação mental, ética, identitária, cultural, social e política. Quando voltam à escola carregam esse acúmulo de formação e de aprendizagens". (ARROYO, 2005, p. 25).

\section{Considerações finais}

Este artigo buscou contribuir na discussão das práticas de educação popular na formação do educador na área de Educação de Jovens e Adultos, com base na Pedagogia libertadora de Freire, sobretudo, algumas categorias presentes na obra Pedagogia do Oprimido. O artigo mostra como as categorias dialogicidade e inédito viável, presente nesta obra e em outros escritos do autor colaboram na reflexão sobre a formação inicial e continuada de professores na EJA. O texto chama a atenção para a atualidade do pensamento freireano no tocante ao reconhecimento do saber de experiência feito do educando. Ao mesmo tempo, ressalta como uma proposta de formação docente pautada nas premissas da dialogicidade, educação para a mudança e inédito viável encontram uma ampla argumentação, na medida em que seus fundamentos apoiam-se em pilares que norteiam uma educação humanizadora. Portanto, tais conceitos se mantém atuais e necessários para se (re) pensar as práticas pedagógicas, o currículo e a formação docente na educação de jovens e adultos. 


\section{Referências}

ARROYO, Miguel. Educação de Jovens e Adultos - um campo de direitos e de responsabilidade pública in: SOARES, L. et ali (orgs.) Diálogos na educação de jovens e adultos. Belo Horizonte: Autêntica, 2005.

BARRETO, Vera. Paulo Freire para educadores. São Paulo: Arte Ciência, 1998.

BEISIEGEL, Celso de Rui. Estado e educação popular: Um estudo sobre a educação de adultos. São Paulo: Pioneira, 1974.

BRANDÃO, Carlos Rodrigues. A educação popular 40 anos depois in: A educação popular na escola cidadã. Petrópolis, RJ: Vozes, 2002b.

. e RUMMERT, S. Formação de profissionais para a educação de jovens e adultos

trabalhadores Educação em revista. n. ${ }^{\circ}$ 30, Belo Horizonte, FAE/UFMG, 1999.

BRASIL. CONSELHO NACIONAL DE EDUCAÇÃO [Parecer aprovado sobre as Diretrizes Curriculares Nacionais para a Educação de Jovens e Adultos] Brasília:CNE, 2001.

FREIRE, Paulo. Pedagogia do Oprimido. 37. ed. São Paulo: Paz e Terra, 1987.

. Pedagogia da autonomia. São Paulo: Paz e Terra, 1996.

. Pedagogia da indignação.São Paulo: ed. Unesp, 2000.

GIOVANETTI, Maria. A. C. A formação de educadores de EJA: o legado da educação popular in: SOARES et ali (orgs.) Diálogos na educação de jovens e adultos. Belo Horizonte: Autêntica, 2005.

OLIVEIRA, Inês. Barbosa; PASSOS, M. C. P. ; PAIVA, Jane . Currículo em EJA: práticas culturais, direito de aprender por toda vida e ecologia de saberes. Revista Educação em questão (online), v. 54, p. 113, 2016.

OLIVEIRA, Inês. B.; COUTINHO, M. C. G.C. Evasão na EJA - Histórias de abandono? Usos e táticas de praticantes na autogestão da vida. Arquivos Analíticos de Políticas Educativas. v.21, n. 77, p.1 - 20, 2013.

ROMANELLI, Geraldo. Questões teóricas e metodológicas nas pesquisas sobre família e escola. in: ROMANELLI, Geraldo (Org.). Itinerário de pesquisa. Perspectiva qualitativa em sociologia da educação. Rio de Janeiro: DP\&A, 2003.

SOARES, Leôncio e PEDROSO, Ana P. F. Dialogicidade e a formação de educadores na EJA: as contribuições de Paulo Freire. Revista Educação v.15, n. 2, maio.agosto 2013

STRECK, Danilo. Algumas lições do mestre. Revista do Instituto Humanistas Unisinos, São Leopoldo/RS, Ano VII, n. 223, p.6-8, jun. 2007. 
SERRA, E.; VENTURA, J.; ALVARENGA, M.; REGUERA, E.. Interrogando o direito à educação: oferta e demanda por Educação de Jovens e Adultos no estado do Rio de Janeiro. Crítica Educativa. Sorocaba/SP. v. 3, n. 3, p. 25-41, 2017.

\footnotetext{
i Professora Adjunta da Faculdade de Educação e do Programa de Pós-graduação em Educação da Universidade de Brasília . É Pedagoga com mestrado em Educação pela Universidade Federal de Uberlândia (2000) e doutorado em Educação pela Universidade Federal de Minas Gerais (2006).
} 